\title{
SPONTANEOUS RECTAL DISCHARGE OF A RETAINED SURGICAL PAD
}

\author{
Hasan BESIM 1 冈 \\ ${ }^{1}$ Department of General Surgery, Near East University Hospital, Nicosia, Cyprus \\ Received 12 April 2021, Accepted 21 May 2021 \\ https://doi.org/10.31688/ABMU.2021.56.2.16
}

\section{Abstract}

Introduction. Postoperative foreign body retention is a well-known and rare complication of all types of surgical interventions. The clinical presentation of a patient with an abdominal retained foreign body is generally as an infectious syndrome, such as intraabdominal sepsis, peritonitis, abscess formation, intestinal perforation or obstruction. However, these foreign bodies may remain dormant for years or may generate vague symptoms. Contained rupture and spontaneous passage through a hollow organ and subsequent rectal expulsion are very rare outcomes.

Case presentation. We present the case of a 23 years-old female patient previously operated who had a spontaneous rectal expulsion about two months after the operation, with no need for any further operative intervention.

Conclusions. The spontaneous expulsion of a postoperative foreign body is a very rare but possible situation. This is a very serious medicolegal problem and many safe operating room practices are implemented to minimize the occurrence of this complication, defined as gossypiboma or textiloma, as the most common foreign body retained is a surgical sponge.

Keywords: foreign bodies, gossypiboma, surgical sponges.

\section{Résumé}

Elimination rectale spontanée d'un tampon chirurgical retenu

Introduction. La rétention de corps étrangers postopératoire est une complication bien connue et rare de tous les types d'interventions chirurgicales. La présentation clinique d'un patient avec un corps étranger retenu dans l'abdomen est généralement un syndrome infectieux, tel qu'une septicémie intra-abdominale, une péritonite, une formation d'abcès, une perforation ou une obstruction intestinale. Cependant, ces corps étrangers peuvent rester en état latent pendant des années ou peuvent générer de vagues symptômes. La rupture contenue et le passage spontané à travers un organe creux et l'expulsion rectale ultérieure sont des résultats très rares.

Présentation du cas. Nous présentons le cas d'une patiente de 23 ans, précédemment opérée, qui a eu une expulsion rectale spontanée environ deux mois après l'opération, sans aucune intervention chirurgicale supplémentaire.

Conclusions. L'expulsion spontanée d'un corps étranger postopératoire est très rare, mais possible. Il s'agit d'un problème médico-légal très grave et de nombreuses pratiques sécuritaires en salle d'opération sont mises en œuvre pour minimiser la survenue de cette 
complication, définie comme un gossypibome ou un textilome, car le corps étranger le plus couramment retenu est une éponge chirurgicale.

Mots-clés: corps étrangers, gossypibome, éponges chirurgicales.

\section{INTRODUCTION}

Postoperative retention of foreign bodies is a rare, but well-known complication, with potential medicolegal implications ${ }^{1}$. A postoperative retained surgical sponge is defined as gossypiboma (Gossypium: cotton, Boma: place of concealment) or textiloma and is usually under-reported due to legal reasons ${ }^{1-3}$. The clinical presentation is highly variable, ranging from a septic syndrome, intense inflammatory reaction, perforation, obstruction, to an incidental discovery during a diagnostic or surgical procedure ${ }^{4,5}$. Although spontaneous, transmural migration of peritoneal cavity foreign bodies into hollow organs and spontaneous expulsion is described in the medical literature, being a very rare and unusual complication ${ }^{2}$. This case report describes a spontaneous rectal expulsion of a retained surgical pad left after a caesarean section.

\section{Case report}

A 23-year-old woman presented to the Cengiz Topel District Hospital, Yeșilyurt, Cyprus, with mild right lower abdominal pain and a sense of fullness in the same region. Only a mild right lower quadrant pain was reported at the abdominal examination, without any evidence of guarding of a mass. As medical history, the patient had a caesarean section performed in another medical institution around two months earlier, without a routine postoperative follow-up, because of social reasons. An abdominal computed tomography (CT) was performed in that institution, which showed a complex abdominal mass, with the possible diagnosis of diverticulitis. A colonoscopy was performed in the same institution, which was normal up to the hepatic flexure and the procedure was terminated because of patient discomfort. In my interpretation, the CT scan (Figure 1) showed a complex mass containing spongy appearance and radiopaque markers. A direct abdominal X-ray was performed, which confirmed the radiopaque markers extending from the right to the left of the abdomen, with the diagnosis of migrating gossypiboma (Figure 2).

As the patient was stable, without any acute symptoms of obstruction, intra-abdominal infection,

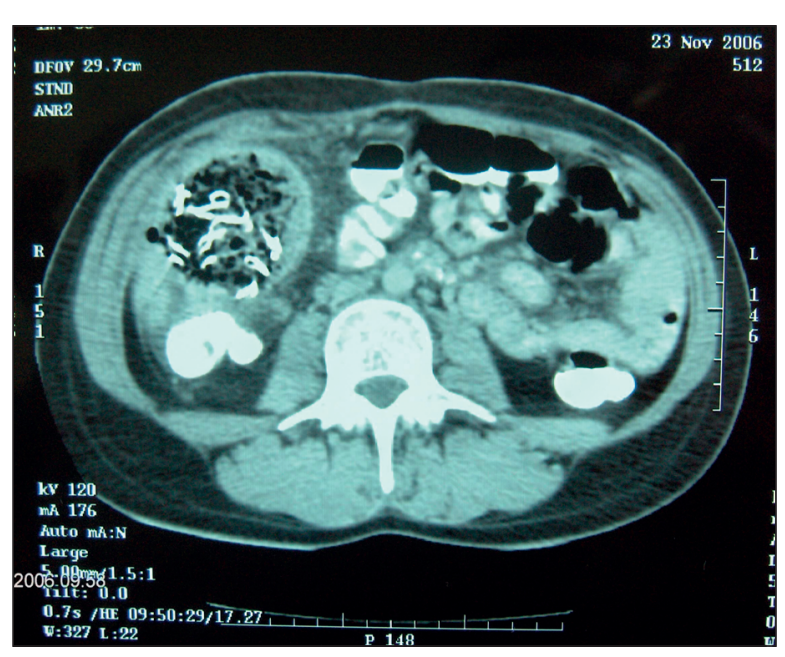

Figure 1. The typical appearance of a complex mass containing air bubbles and radiopaque markers.

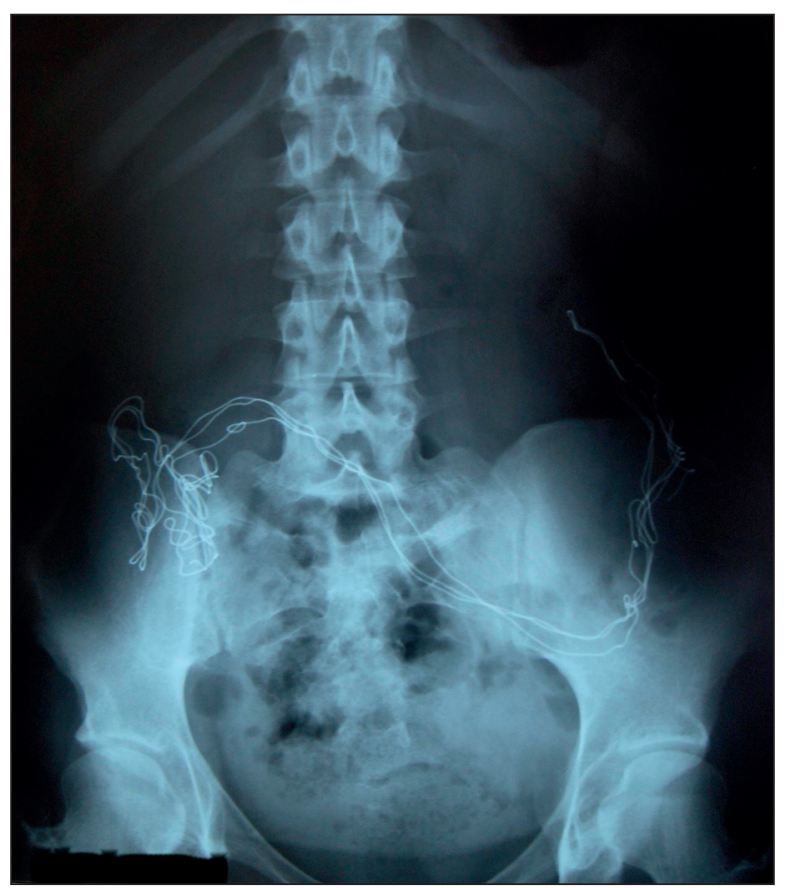

Figure 2. Plain abdominal X-ray of the patient with gossypiboma.

septic findings or perforation, and there was a migration effect, the elective surgical removal of the foreign material was planned in a few days. The patient passed the laparotomy sponge (Figure 3) with a bowel movement three days after she was examined 


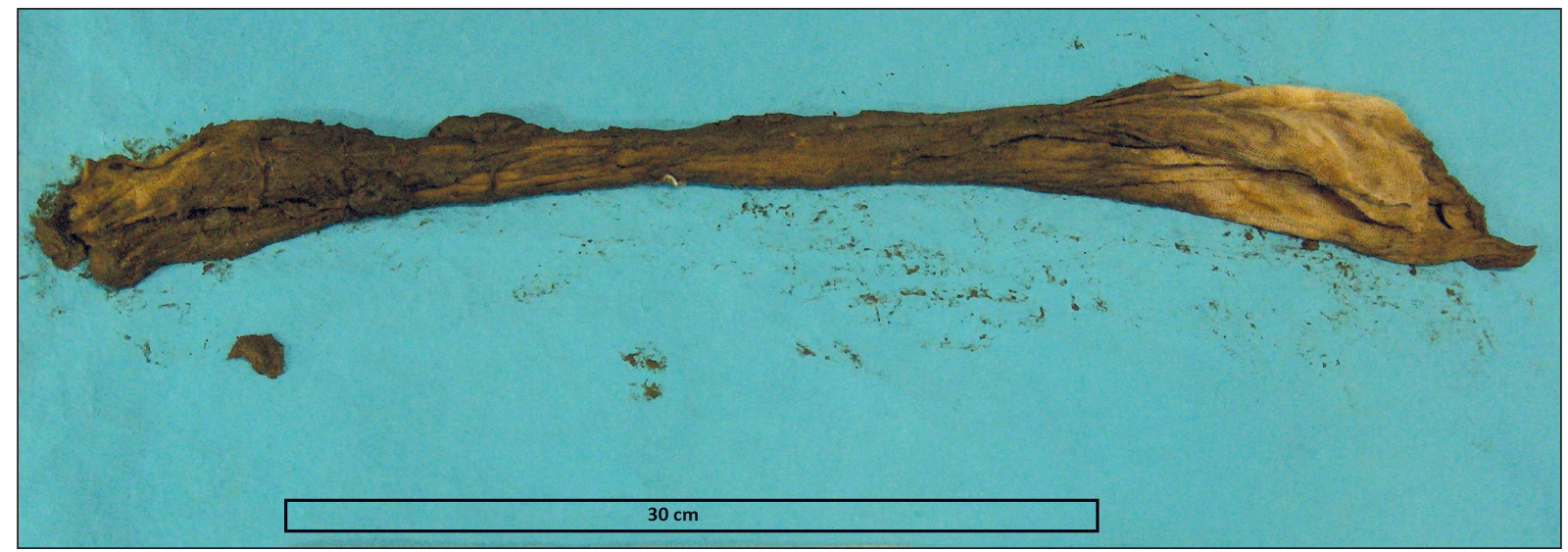

Figure 3. Laparotomy pad, discharged with a bowel movement.

at the hospital, presenting only mild right lower abdominal discomfort. Routine laboratory tests were normal. The control abdominal CT scan revealed a right abdominal collection at the site of the previous gossypiboma (Figure 4). Parenteral antibiotic treatment was administered, to preclude the infection of the cavity. The patient was followed and the cavity of the gossypiboma disappeared after one month. The patient is in good health and has no complaints at the present time.

\section{Discussion}

Gossypiboma is a known surgical entity, thought to be under-reported due to medical and legal reasons ${ }^{1-3}$. The exact incidence is not known, but it is estimated as one case in 1,000 to 1,500 laparotomies $^{5.7}$. The presentation of the patient can be as an acute abdomen and intraabdominal sepsis or relatively delayed and insidious, with vague abdominal complaints. Acute inflammation, abscess formation, peritonitis, perforation or intestinal obstruction can be seen because of a peritoneal foreign body ${ }^{3}$. There are reports in which the patients are misdiagnosed with ovarian or intra-abdominal tumours and the final diagnosis is in fact gossypiboma ${ }^{3}$. Cotton sponges and towels are the most common peritoneal foreign bodies ${ }^{7}$. They are inert, but when left in the peritoneal cavity they may serve as an infectious nidus, leading to abscess formation. If they are relatively aseptic, then the inflammatory reaction is low-grade, leading to encapsulation and granuloma formation. This may remain dormant for years or may generate symptoms like pain, palpable mass, or the patient may present with intestinal obstruction. The foreign body can erode through the wall of an adjacent loop of the bowel, leading to fistula formation. If the area is encapsulated with omentum and other intraabdominal organs, this type of "contained rupture"

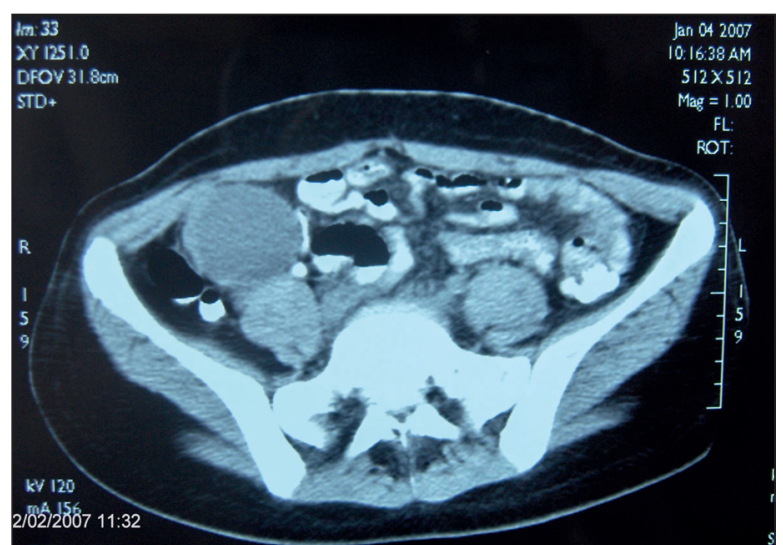

Figure 4. Right abdominal collection at the prior site of gossypiboma.

does not lead to generalized peritonitis and the calibration of the foreign body decides the outcome. If it is small enough or it may be shaped for effective passage through an intestinal lumen, peristaltic activity facilitates intraluminal passage and subsequent spontaneous expulsion with feces ${ }^{8}$.

Sometimes, the presentation is delayed months or years after the primary operation. Incidental discovery of a foreign body can be seen during a radiological examination or a laparotomy performed for another reason ${ }^{4,5}$. The easiest way of diagnosis is a direct abdominal X-ray if the foreign body is radiopaque or contains such markers. The ultrasonographic finding is generally a well-defined mass, containing heterogeneous internal echoes, with a hypoechoic rim and a strong posterior shadow'. CT scan generally demonstrates a well-circumscribed "spongy-form mass" with varying air and soft tissue densities, .

The treatment usually depends on the presentation of the case. In the case of peritonitis and abscess formation, obstruction and fistulization, emergency surgical intervention is needed for extraction of the 
foreign body, peritoneal debridement and cleansing. Additional surgical procedures should be tailored for each case, according to the intraoperative findings. In case of intestinal fistula formation or obstruction, resection of the involved segment may be needed.

In our case, the early surgical treatment was not considered, as the patient was stable, aseptic, the foreign material was distally migrated and finally discharged with a bowel movement. The internal opening or in other words the "contained rupture" of the bowel closed spontaneously under medical supervision with parenteral antibiotics.

\section{Conclusion}

The presentation of a patient with retained sponge may be variable. Some patients may be incidentally diagnosed and others may present with acute abdominal findings. Transmural migration and spontaneous rectal discharge are also possible but very rarely.

The spontaneous expulsion of a postoperative foreign body is very rare, but possible. This is a very serious medicolegal problem and many safe operating room practices are implemented to minimize the occurrence of this complication.

\section{Author Contributions:}

H.B. was responsible for the diagnostic procedures, clinical diagnosis, and treatment decisions. H.B. wrote the manuscript.

\section{Compliance with Ethics Requirements:}

"The author declares no conflict of interest regarding this article"

"The author declares that all the procedures and experiments of this study respect the ethical standards in the Helsinki Declaration of 1975, as revised in 2008(5), as well as the national law. Informed consent was obtained from the patient included in the study"

"No funding for this study"

\section{Acknowledgements:}

None

\section{References}

1. Debnath D, Buxton JK, Koruth NM. Two years of wait and 7000 miles of journey: the tale of a gossypiboma. Int Surg. 2005;90(3):130-3.

2. Godara R, Marwah S, Karwasra RK, et al. Spontaneous transmural migration of surgical sponges. Asian J Surg. 2006;29(1):44-5.

3. Zbar AP, Agrawal A, Saeed TI, Utidjian RA. Gossypiboma revisited: a case report and review of the literature. JR Coll Surg Edinb 1998;43:417-18.

4. Besim H, Korkmaz A, Hamamcı O, Karaahmetoğlu S, Review of eight cases of insulinoma. East African Medical Journal 2002; 79(7):368-372.

5. Dhillon JS, Park A. Transmural migration of a retained laparotomy sponge. The American Surgeon 2002;68, 603-5.

6. Brennan TA, Leappe LL, Laird NM, et al. Incidence of adverse events and negligence in hospitalized patients. New England Journal of Medicine 1991; 7:324, 370-6.

7. Hinrichs C, Methratta S, Ybasco AC. Gossypiboma treated by colonoscopy. Pediatr Radiol 2003;33:261-262.

8. Hyslop J, Maull K. Natural history of the retained surgical sponge. South Med J 1982;75:657-660.

9. Rajagopal A, Martin J. Gossypiboma - A surgeon's legacy. Dis Colon Rectum 2002;45:119-120. 